\title{
(C) OPEN ACCESS \\ Self-management capability in patients with long-term conditions is associated with reduced healthcare utilisation across a whole health economy: cross-sectional analysis of electronic health records
}

- Additional material is published online only. To view please visit the journal online (http://dx.doi.org/10.1136/ bmjqs-2017-007635).

Data Analytics, The Health Foundation, London, UK

\section{Correspondence to} Dr Sarah R Deeny, Data Analytics, The Health

Foundation, London WC2E 9RA UK; Sarah.Deeny@health.org.uk

Received 21 November 2017 Revised 26 March 2018 Accepted 23 April 2018 Published Online First 23 August 2018

\section{A) Check for updates}

To cite: Barker I, Steventon A, Williamson $\mathrm{R}$, et al. BMJ Qual Saf

2018;27:989-999.

Isaac Barker, Adam Steventon, Robert Williamson, Sarah R Deeny

Objective To quantify the association between patient self-management capability measured using the Patient Activation Measure (PAM) and healthcare utilisation across a whole health economy.

Results 12270 PAM questionnaires were returned from 9348 patients. In the adjusted analyses, compared with the least activated group, highly activated patients (level 4) had the lowest rate of contact with a general practitioner (rate ratio: $0.82,95 \% \mathrm{Cl} 0.79$ to 0.86 ), emergency department attendances (rate ratio: $0.68,95 \% \mathrm{Cl} 0.60$ to 0.78 ), emergency hospital admissions (rate ratio: $0.62,95 \% \mathrm{Cl} 0.51$ to 0.75 ) and outpatient attendances (rate ratio: $0.81,95 \% \mathrm{Cl}$ 0.74 to 0.88 ). These patients also had the lowest relative rate (compared with the least activated) of 'did not attends' at the general practitioner (rate ratio: $0.77,95 \% \mathrm{Cl} 0.68$ to 0.87), 'did not attends' at hospital outpatient appointments (rate ratio: $0.72,95 \% \mathrm{Cl} 0.61$ to 0.86 ) and self-referred attendance at emergency departments for conditions classified as minor severity (rate ratio: $0.67,95 \% \mathrm{Cl} 0.55$ to 0.82 ), a significantly shorter average length of stay for overnight elective admissions (rate ratio $0.59,95 \% \mathrm{Cl}$ 0.37 to 0.94 ), and a lower likelihood of 30 - day emergency readmission (rate ratio: $0.68,95 \% \mathrm{Cl} 0.39$ to 1.17 ), though this did not reach significance.

Conclusions Self-management capability is associated with lower healthcare utilisation and less wasteful use across primary and secondary care.

\section{INTRODUCTION}

Improving outcomes for the growing number of people living with long-term conditions, while managing a rising demand for health services, is a challenge faced both by physicians and policymakers across health systems in developed countries. Such patients use the majority of healthcare services, with 70\% of National Health Service (NHS) spending being for patients with long-term conditions. However, these patients are often expected to manage their conditions at home for much of their lives, spending under $1 \%$ of their time in contact with health professionals. ${ }^{1}$ It has been long recognised that self-management should form an important part of any model of care for those living with long-term conditions. ${ }^{2}$ More recently, the importance of self-management in reducing demand for services has been recognised as part of the NHS 5-year forward view, ${ }^{3}$ and is a central pillar of prominent initiatives such as the accountable care organisations ${ }^{4}$ and some patient-centred medical homes. ${ }^{5}$

A meta-analysis of randomised controlled trials of interventions to reduce readmissions found that approaches that support patient capability for self-management were more effective than other approaches. ${ }^{6}$ However, several prominent programmes with substantial self-management components have seen no change in healthcare utilisation (including the NHS integrated care pilots ${ }^{7}$ and disease management initiatives ${ }^{8}$ ), while a systematic review of case management interventions found no evidence that it reduces secondary care utilisation or costs. ${ }^{9}$ Improving the impact of such interventions is difficult as there is surprisingly little evidence surrounding the varying capability of those with long-term conditions to engage in self-management. For example, there is limited evidence as to the impact of self-management outside of acute care, ${ }^{10}{ }^{11}$ which could be an important consideration when designing self-management programmes that are often delivered by primary care teams. More evidence is therefore needed to 
understand the distribution of self-management capability, and the link between self-management and healthcare utilisation in patients with long-term conditions.

There are a number of measures to assess self-management capability, for example as part of an assessment of the quality of patient chronic care ${ }^{11}$ or domains of patient efficacy. ${ }^{12}$ One validated metric, in use, to identify and quantify the knowledge, skills and confidence a patient has in managing their own health is the Patient Activation Measure (PAM), piloted for the first time in the NHS between 2014 and 2016 by five commissioners and the renal registry in England. ${ }^{13}$ The PAM comprises 13 questions relating to knowledge, skills and confidence, and was originally developed in the USA to provide information to tailor care to the patient's activation level, for example through interventions such as coaching or education. ${ }^{14}$ Previous research has shown that more activated patients have lower healthcare costs ${ }^{15}$ and better health outcomes than other patients. ${ }^{15-20}$ However, all large studies on this topic have focused on healthcare providers in the USA. ${ }^{12-14} 1617$ No studies have considered healthcare systems that are free at the point of use, such as the NHS in the UK, which also has a prominent role for primary care as a gatekeeper to secondary and specialised care. Most studies have focused on the link between the PAM and emergency and inpatient utilisation of secondary care. ${ }^{19-21}$ To our knowledge there are no studies which have comprehensively quantified the link between self-management and health service utilisation across the health economy, including primary care, using electronic health records. Furthermore, no studies have explicitly considered how mental health, physical health, multimorbidity or socioeconomic deprivation (which in England is measured at the area of patient's residence level using the Index of Multiple Deprivation 2010 (IMD) ${ }^{22}$ ) influences the relationship between activation and utilisation. When designing interventions that need to be tailored to a patient's need, it is important that clinicians have evidence as to which patient subgroups may benefit most from self-management interventions. Finally, previous studies have focused predominantly on hospital admissions or emergency department attendances that are, in many circumstances, a necessary and desirable part of patient care. None have examined more specific markers of inefficient or wasteful usage which could be reduced without an impact on quality of care.

In this study, we exploit a unique database of over 12000 patient activation scores linked to longitudinal data on the utilisation of primary and secondary care within an urban health economy (Islington Clinical Commissioning Group (CCG)). This is the only PAM pilot site, in the English NHS, which surveyed self-management capability from all patients with longterm conditions. Controlling for patient demographics and clinical characteristics, and multiple responses per patient, we quantify the association between patient activation and the frequency with which these patients access primary and secondary care. Further, we examine the rate at which patients experience 30 -day emergency readmissions to hospital, and their length of stay for elective and emergency admissions to hospital. We then examine the association with wasteful utilisation, which we define as 'did not attends' with general practitioners and outpatient specialists, and self-referrals to emergency departments for conditions classified as minor severity.

\section{METHODS}

\section{Patient Activation Measure}

The PAM is a validated tool of 13 questions which assesses a patient's knowledge, skills and confidence in managing their own health (further description in online supplementary appendix 1). Answers are weighted and combined to provide a score on a scale from 0 to 100. PAM scores between 1 and 99 are considered to be valid responses, ${ }^{23}$ and allow respondents to be categorised into one of four predefined levels, ranging from level 1 (patients who do not actively contribute to their healthcare) to level 4 (patients who are proactive in managing their health and engage in healthy behaviours). A score of less than 47.0 places a patient in level 1, 47.1-55.1 level 2, 55.2-72.4 level 3, and more than 72.5 in level 4.

\section{Study setting}

This was an observational, retrospective study using linked primary care, secondary care and small arealevel socioeconomic individual longitudinal data from 34 general practices in the Islington CCG, a large urban healthcare organisation responsible for arranging for care to be provided to a population of around 250000 people in London. ${ }^{24}$ A description of the method used to collect the PAM questionnaire data is provided in online supplementary appendix 1 . Briefly, questionnaires were collected in November 2014 and November 2015 from all local patients aged 18 years or over with long-term conditions (severe mental health conditions (including schizophrenic disorders, bipolar affective disorder, psychosis, manic disorder), asthma, cancer (from 2003), chronic depression, chronic heart disease (including ischaemic heart disease and other current complications following acute myocardial infarction), chronic kidney disease (stages 3-5), chronic obstructive pulmonary disease (including all-stage chronic obstructive pulmonary disease, emphysema or other chronic obstructive airways disease), chronic liver disease, dementia, diabetes, heart failure, hypertension and stroke (or transient ischaemic attack)). Conditions were identified by participating general practices by applying a predefined search criteria to the electronic medical record. Search terms were based on the set of READ codes used for the quality and outcomes 
framework, a pay-for-performance system used within primary care in England. ${ }^{25}$

\section{Study cohort and data set}

We studied all patients who were aged 18 or over and eligible to receive both of the PAM questionnaires at any of the 34 participating general practices, who returned a questionnaire in either November 2014 or November 2015. We excluded any patients who had PAM scores of 0 or 100 from our analysis. ${ }^{23}$ We obtained pseudonymised, person-level data on utilisation of primary and secondary care spanning the period from January 2013 to April 2016, which we linked to small area-level socioeconomic deprivation scores based on the residence of the patient.

\section{Exposure, outcomes and study covariates}

The exposure of interest was PAM level. As the questionnaire was sent out twice, it is possible for patients to have two recorded PAM responses. In this case, each response was treated as two separate observations, nested within one patient. For each PAM response, exposure, outcomes and study covariates were calculated.

Outcome variables relating to healthcare utilisation were calculated for two, 1-year periods, each spanning 6 months either side of when the PAM score was collected (ie, May 2014-April 2015, and May 2015April 2016). Our outcome variables were the number of contacts with a general practitioner (face-to-face or telephone contacts), the number of appointments with specialists in hospital-based outpatient settings that the patient attended, the number of attendances at emergency departments, the number of emergency inpatient admissions to hospital and the number of non-regular elective inpatient admissions to hospital. For patients who had an admission to hospital during the observation periods, five further outcome measures were calculated: whether elective and emergency hospital admissions involved an overnight stay, the length of hospital stay (calculated as the number of nights in hospital) for elective and emergency admissions, and 30-day emergency readmission rates. ${ }^{26}$ Further details of the selection of this cohort and definition of the outcome variables are provided in online supplementary appendix 2. Finally, three further outcome variables were calculated for all patients and intended to reflect wasteful usage, namely the number of contacts with a general practitioner that the patient did not attend, the number of outpatient appointments that were not attended, and the number of emergency department attendances that were classified as being for conditions of minor severity and that were additionally self-referrals by the patient. ${ }^{27}$

These outcome measures were calculated using the routine data sets. 'Did not attends' were defined as occurring if a patient unexpectedly does not attend an appointment. Emergency inpatient admissions are those occurring through an emergency department or via direct and urgent referrals from a general practitioner or other health professionals. Non-regular elective inpatient admissions are those resulting from a consultant referral and exclude regular admissions, such as for dialysis.

Covariates tested in the model specification were patients' age in years when the PAM response was collected; male or female sex; predicted risk of emergency hospital admission over 12 months subsequent to the PAM collection from the Combined Predictive Model $^{2829}$; the national and local quintile of IMD 2010 at the small area of patients' residence ${ }^{22}$; counts of long-term physical conditions; counts of mental health conditions also derived from the primary care record (derived from the primary care record of the patient as described in detail in online supplementary appendix 1 ); and individual long-term condition(s) as dichotomous variables. Final model specification for the adjusted model was chosen using the Akaike information criterion goodness-of-fit statistic. ${ }^{30}$

\section{Statistical methods}

We fitted separate regression models for each outcome to assess their relationship with the PAM, both adjusted and unadjusted for the study covariates listed above.

For the outcome measures that concerned utilisation, we used mixed-effects negative binomial, repeated measurement regression models with a log link. We use repeated measurements to account for the fact that it is possible for patients to have two recorded PAM levels and therefore two observations in the analysis. For 'did not attend' outcomes, models included a covariate to control for the total number of contacts with a general practitioner or appointments in an outpatient setting. Rate ratios were calculated for the differences between the PAM levels, using level 1 (the least activated) as the reference level.

For observation periods that had a relevant admission to hospital, we first used a mixed-effects logistic regression model to determine whether admissions of each type (elective and emergency) resulted in an overnight stay. We then ran mixed-effects negative binomial models predicting the length of stay for elective and emergency admissions, for admissions that included an overnight stay.

Using a mixed-effects negative binomial model, including an offset for the number of admissions, we predicted the rate of 30-day emergency readmission, given an eligible hospital admission (as defined in online supplementary appendix 2). In all analyses, we accounted for multiple observations. Further details are provided in online supplementary appendix 3.

To determine whether our findings were sensitive to the definition of the observation window used, we repeated our analysis, restricting our observation window to the 6 months following PAM collection. 


\section{Analysis regarding patient subgroups}

We investigated whether the association between PAM and health care utilisation varied between patient subgroups. Interactions were examined for patients with two or more long-term conditions, patients with three or more long-term conditions, patients with no mental health long-term conditions, patients with a mental health long-term condition, patients aged under 75 , patients aged 75 and over, patients living in an area in the most deprived quintile, and patients living in the four least deprived quintiles. This analysis was carried out by rerunning the adjusted mixed-effects negative binomial model described above, replacing the PAM variable with an interaction term between PAM and a categorical variable for the subgroups. Further details are provided in online supplementary appendix 3 .

\section{Patient involvement}

Patients were not directly involved in this data analysis study; however, the use of PAM in healthcare providers in the NHS and the acceptability to patients were examined through a separate qualitative study that included patient interviews. ${ }^{31}$ While patients were not involved in setting the research question or the outcome measures presented here, interim findings were presented at meetings that included patient representatives and their input influenced the interpretation of findings.

\section{RESULTS}

From 34 general practices, 37635 patients were identified as having long-term conditions and were sent a questionnaire in both November 2014 and November 2015. Of the patients, $6470(17.2 \%)$ returned a valid questionnaire in 2014 and $5800(15.4 \%)$ returned a questionnaire in 2015, meaning 12270 recorded PAM observations from 9348 patients were included in the final analysis cohort, as described in online supplementary appendix 4. Patients were registered with their general practice for a median of 15 years (IQR 9-23 years). The average age of patients was 67 years and $52.2 \%$ of the cohort were female; $94.2 \%$ of patients had a physical long-term condition, while $28.7 \%$ had a mental health long-term condition (table 1). Reflecting the nature of the Islington area, the clear majority (94.2\%) of patients resided in areas ranked within the two most deprived IMD quintiles nationally. The non-responding cohort was younger, with lower healthcare utilisation and fewer comorbid conditions (online supplementary appendix 5), although IMD was consistent with the response group.

Of the 12270 observations, $22 \%$ were in the least activated band (level 1; $\mathrm{n}=2704$ ), 19\% were in level $2(\mathrm{n}=2337), 46 \%$ were in level $3(\mathrm{n}=5591)$, and $13 \%$ were in the most highly activated band (level 4 , $\mathrm{n}=1638$ ). Patients in level 1 were more likely to be female, were older and lived in more deprived areas than the cohort as a whole. Patients in levels 1 and 2 had higher rates of multimorbidity and mental health condition(s) than more activated patients in levels 3 and 4 (table 1). Except for elective hospital admissions, patients with higher levels of activation tended to have fewer contacts and less wasteful usage of the health economy than patients at lower levels of activation (table 1). However, as shown in table 1, elective admissions showed a distinct 'U-shaped' pattern, with level 1 having the highest rate of these admissions and level 4 the second highest rate.

One thousand five hundred and seventy-seven observation periods had at least one hospital admission that could have led to a readmission according to the criteria used $^{32}$; a higher proportion of admissions for patients in level 1 led to a readmission than the other levels of activation. The per cent of observation periods with an overnight elective admission $(n=679)$, out of observation periods with any length elective admission $(n=2848)$, was similar for all PAM levels. The mean length of stay for overnight elective admissions was longer for patients in PAM level 1. In 1620 observation periods an emergency admission occurred, and in 1248 of these an overnight emergency admission occurred. Again, the per cent of observation periods with an overnight emergency admission, out of those with any length elective admission, was similar for all PAM levels. The mean length of stay for overnight emergency admissions was similar across PAM levels (as shown in online supplementary appendix 2).

\section{Statistical analysis}

As shown in table 2, after adjusting for clinical and demographic characteristics, higher activation was associated with lower rates of healthcare utilisation, with the exception of elective admissions which showed a different pattern. Compared with patients with activation level 1 , those with the highest level of activation (level 4) had the lowest rate of contact with a general practitioner (rate ratio: 0.82, 95\% CI 0.79 to 0.86), emergency department attendances (rate ratio: $0.68,95 \% \mathrm{CI} 0.60$ to 0.78 ), emergency admissions (rate ratio: $0.62,95 \% \mathrm{CI} 0.51$ to 0.75 ) and outpatient attendances (rate ratio: $0.81,95 \%$ CI 0.74 to 0.88 ). Moreover, compared with patients with activation level 1, those with the highest level of activation (level 4) had the lowest rate of 'did not attend' with a general practitioner (rate ratio: $0.77,95 \%$ CI 0.68 to 0.87 ) and 'did not attend' at hospital outpatient appointments (rate ratio: $0.72,95 \% \mathrm{CI} 0.61$ to 0.86 ). Patients in the highest level of activation also had the lowest relative rate of attendance at emergency departments for conditions classified as minor severity that were self-referrals, compared with those with level 1 (rate ratio: $0.67,95 \% \mathrm{CI} 0.55$ to 0.82 ). While levels 2,3 and 4 are associated with lower elective admissions when compared with patients in level 1 , patients in level 3 had the largest difference (rate ratio: 0.77, $95 \%$ CI 0.69 to 0.87 ). 
Table 1 Descriptive statistics observation periods where a PAM questionnaire was returned, split by PAM level (1-4)

\begin{tabular}{|c|c|c|c|c|c|}
\hline & $\begin{array}{l}\text { PAM level } 1 \\
\text { (least activated) }\end{array}$ & PAM level 2 & PAM level 3 & $\begin{array}{l}\text { PAM level } 4 \\
\text { (most activated) }\end{array}$ & Overall \\
\hline & $(n=2704)$ & $(n=2337)$ & $(n=5591)$ & $(n=1638)$ & $(n=12270)$ \\
\hline Healthcare utilisation & Mean (SD) & Mean SD & Mean SD & Mean SD & Mean SD \\
\hline Contacts with a general practitioner & $10.52(8.66)$ & $8.90(7.6)$ & $8.19(7.40)$ & $7.50(6.84)$ & $8.75(7.73)$ \\
\hline Emergency department attendances & $0.73(1.99)$ & $0.49(1.27)$ & $0.47(1.11)$ & $0.42(1.00)$ & $0.52(1.37)$ \\
\hline Elective inpatient admissions & $0.61(2.38)$ & $0.39(1.2)$ & $0.39(1.39)$ & $0.58(5.17)$ & $0.47(2.45)$ \\
\hline Emergency inpatient admissions & $0.28(0.86)$ & $0.18(0.58)$ & $0.17(0.62)$ & $0.15(0.64)$ & $0.19(0.68)$ \\
\hline Attended outpatient appointments & $6.72(9.55)$ & $5.86(8.64)$ & $5.48(8.51)$ & $5.05(7.88)$ & $5.77(8.71)$ \\
\hline 'Did not attend' contacts with a GP & $0.75(1.50)$ & $0.52(1.10)$ & $0.44(1.05)$ & $0.36(0.81)$ & $0.51(1.15)$ \\
\hline 'Did not attend' outpatient appointments & $0.36(0.98)$ & $0.24(0.72)$ & $0.21(0.74)$ & $0.20(0.70)$ & $0.25(0.79)$ \\
\hline Minor self-referrals to emergency departments & $0.20(0.64)$ & $0.18(0.68)$ & $0.15(0.51)$ & $0.12(0.39)$ & $0.16(0.56)$ \\
\hline \multicolumn{6}{|l|}{ Other patient characteristics } \\
\hline Age in years at the time of the questionnaire & $67.36(14.17)$ & $67.47(13.28)$ & $67.21(13.37)$ & $64.37(12.96)$ & $66.92(13.52)$ \\
\hline Number of physical long-term conditions* & $2.05(1.43)$ & $2.00(1.30)$ & $1.92(1.29)$ & $1.80(1.19)$ & $1.95(1.31)$ \\
\hline Number of mental health long-term conditionst & $0.44(0.59)$ & $0.29(0.50)$ & $0.28(0.49)$ & $0.25(0.47)$ & $0.31(0.52)$ \\
\hline Number of physical long-term conditions* & Frequency (\%) & Frequency (\%) & Frequency (\%) & Frequency (\%) & Frequency (\%) \\
\hline 0 & $218(8.1)$ & $129(5.5)$ & $288(5.2)$ & $74(4.5)$ & $709(5.8)$ \\
\hline 1 & $931(34.4)$ & $873(37.4)$ & $2295(41.1)$ & $751(45.9)$ & $4850(39.5)$ \\
\hline 2 & $741(27.4)$ & $675(28.9)$ & $1606(28.7)$ & $464(28.3)$ & $3486(28.4)$ \\
\hline $3+$ & $814(30.1)$ & $660(28.2)$ & $1402(25.0)$ & $349(21.3)$ & $3225(26.3)$ \\
\hline \multicolumn{6}{|l|}{ Number of mental health long-term conditionst } \\
\hline 0 & $1640(60.7)$ & $1706(73.0)$ & $4155(74.3)$ & $1253(76.5)$ & $8754(71.3)$ \\
\hline 1 & $936(34.6)$ & $582(24.9)$ & $1328(23.8)$ & $361(22.0)$ & $3207(26.1)$ \\
\hline $2+$ & $128(4.7)$ & $49(2.1)$ & $108(1.9)$ & $24(1.5)$ & $309(2.5)$ \\
\hline \multicolumn{6}{|l|}{ Index of Multiple Deprivation (national quintile groups) } \\
\hline 1 (most deprived) & $1496(55.3)$ & $1259(53.9)$ & $2902(51.9)$ & $833(50.9)$ & $6490(52.9)$ \\
\hline 2 & $1078(39.9)$ & $949(40.6)$ & $2352(42.1)$ & $690(42.1)$ & $5069(41.3)$ \\
\hline 3,4 or 5 & $130(4.8)$ & $129(5.5)$ & $337(6.0)$ & $115(7.0)$ & $711(5.8)$ \\
\hline \multicolumn{6}{|l|}{ Gender } \\
\hline Female & $1462(54.1)$ & $1214(52.0)$ & $2875(51.4)$ & $853(52.1)$ & $6404(52.2)$ \\
\hline Male & $1242(45.9)$ & $1123(48.0)$ & $2716(48.6)$ & 785 (47.9) & $5866(47.8)$ \\
\hline
\end{tabular}

*Angina, asthma, cancer, chronic heart disease, chronic kidney disease, chronic liver disease, chronic obstructive pulmonary disease, diabetes, myocardial infarction, peripheral arterial disease, stroke/transient ischaemic attack and hypertension.

tDementia, depression and severe mental health.

GP, general practitioner; PAM, Patient Activation Measure.

When analysing emergency readmission to hospital, compared with patients with activation of level 1, those with level 4 had a lower likelihood of 30-day emergency readmission (rate ratio: $0.68,95 \%$ CI 0.39 to 1.17), although this did not reach statistical significance. Compared with patients with activation of level 1 , those at any other level were not associated with statistically significant differences in the likelihood of an elective admission involving an overnight stay (compared with a day case). Furthermore, there were no statistically significant differences in the likelihood of an emergency admission involving an overnight stay, or for emergency admissions the average length of stay of overnight admissions. However, for patients who had at least one overnight elective admission, all PAM levels compared with level 1 were associated with shorter length of stay; patients in level 4, compared with those in level 1 , had the largest difference (rate ratio: $0.59,95 \%$ CI 0.37 to 0.94 ) (see table 2 ).

\section{Analysis of patient subgroups}

Tables 3 and 4 show how the association between activation level and utilisation varied between clinical and demographic subgroups (tested at $\mathrm{p}<0.05$ ). The association was largely the same when compared with the overall cohort when we added an interaction term to analyse patients with $2+$ and $3+$ long-term conditions; however, for those with a long-term mental health condition, the difference in the rate of utilisation between the highest and lowest activated patients was increased (table 3) compared with the overall association found.

When calculating rate ratios for those aged 75 years and over, the association between PAM level and most types of utilisation was no longer statistically significant. The exception was emergency admissions, for which older patients in level 3 had the lowest risk (rate ratio: $0.64,95 \%$ CI 0.53 to 0.77 ) compared with the least activated patients. The association between activation 
Table 2 Repeated measures mixed models predicting utilisation in the period, with an exposure of the PAM level and controlling for other observable confounders

\begin{tabular}{|c|c|c|c|}
\hline Outcome & $\begin{array}{l}\text { PAM level } \\
\text { (vs 1) }\end{array}$ & Adjusted & Unadjusted \\
\hline & & Rate ratio (Cl) & Rate ratio $(\mathrm{Cl})$ \\
\hline \multirow{3}{*}{$\begin{array}{l}\text { Contact with } \\
\text { a general } \\
\text { practitioner }\end{array}$} & 2 & 0.92 (0.88 to 0.95$)$ & 0.88 (0.85 to 0.92$)$ \\
\hline & 3 & 0.87 (0.84 to 0.90$)$ & 0.83 (0.80 to 0.86$)$ \\
\hline & 4 & 0.82 (0.79 to 0.86 ) & 0.77 (0.73 to 0.80$)$ \\
\hline \multirow{3}{*}{$\begin{array}{l}\text { Emergency } \\
\text { department } \\
\text { attendance }\end{array}$} & 2 & 0.76 (0.69 to 0.85 ) & 0.71 (0.64 to 0.79$)$ \\
\hline & 3 & 0.73 (0.66 to 0.79 ) & 0.66 (0.60 to 0.72 ) \\
\hline & 4 & 0.68 (0.60 to 0.78 ) & $0.60(0.53$ to 0.68$)$ \\
\hline \multirow{3}{*}{$\begin{array}{l}\text { Elective } \\
\text { admission }\end{array}$} & 2 & 0.84 (0.73 to 0.96$)$ & 0.83 (0.72 to 0.95$)$ \\
\hline & 3 & 0.77 (0.69 to 0.87 ) & 0.76 (0.67 to 0.85$)$ \\
\hline & 4 & 0.80 (0.68 to 0.94$)$ & 0.76 (0.65 to 0.90$)$ \\
\hline \multirow{3}{*}{$\begin{array}{l}\text { Emergency } \\
\text { admission }\end{array}$} & 2 & 0.71 (0.61 to 0.83 ) & 0.63 (0.54 to 0.74$)$ \\
\hline & 3 & 0.66 (0.58 to 0.75$)$ & 0.57 (0.50 to 0.65$)$ \\
\hline & 4 & 0.62 (0.51 to 0.75 ) & $0.48(0.40$ to 0.59$)$ \\
\hline \multirow{3}{*}{$\begin{array}{l}\text { Attended } \\
\text { outpatient } \\
\text { appointment }\end{array}$} & 2 & 0.90 (0.83 to 0.97 ) & 0.88 (0.82 to 0.95$)$ \\
\hline & 3 & 0.87 (0.82 to 0.94$)$ & 0.85 (0.79 to 0.90$)$ \\
\hline & 4 & 0.81 (0.74 to 0.88 ) & 0.75 (0.69 to 0.82 ) \\
\hline \multirow{3}{*}{$\begin{array}{l}\text { 'Did not attend' } \\
\text { a GP contact }\end{array}$} & 2 & 0.91 (0.82 to 1.00$)$ & 0.87 (0.78 to 0.96$)$ \\
\hline & 3 & 0.85 (0.78 to 0.92$)$ & 0.81 (0.74 to 0.88$)$ \\
\hline & 4 & 0.77 (0.68 to 0.87 ) & 0.74 (0.66 to 0.84$)$ \\
\hline \multirow{3}{*}{$\begin{array}{l}\text { 'Did not attend' } \\
\text { an outpatient } \\
\text { appointment }\end{array}$} & 2 & 0.78 (0.68 to 0.90$)$ & 0.71 (0.62 to 0.82 ) \\
\hline & 3 & 0.68 (0.60 to 0.77 ) & 0.61 (0.54 to 0.69 ) \\
\hline & 4 & 0.72 (0.61 to 0.86$)$ & 0.65 (0.55 to 0.77 ) \\
\hline \multirow{4}{*}{$\begin{array}{l}\text { Minor self- } \\
\text { referral to an } \\
\text { emergency } \\
\text { department }\end{array}$} & 2 & 0.91 (0.77 to 1.07 ) & 0.85 (0.72 to 1.00$)$ \\
\hline & 3 & 0.77 (0.67 to 0.88$)$ & 0.71 (0.62 to 0.81$)$ \\
\hline & 4 & 0.67 (0.55 to 0.82$)$ & $0.63(0.52$ to 0.76$)$ \\
\hline & & Odds Ratio (CI) & Odds Ratio (Cl) \\
\hline \multirow{3}{*}{$\begin{array}{l}\text { 30-day } \\
\text { emergency } \\
\text { readmission }\end{array}$} & 2 & 0.93 (0.63 to 1.40$)$ & 0.91 (0.61 to 1.34) \\
\hline & 3 & $0.78(0.55$ to 1.10$)$ & 0.76 (0.55 to 1.06$)$ \\
\hline & 4 & 0.68 (0.39 to 1.17$)$ & 0.63 (0.37 to 1.08$)$ \\
\hline \multirow{3}{*}{$\begin{array}{l}\text { Likelihood of } \\
\text { an elective } \\
\text { admission } \\
\text { resulting in an } \\
\text { overnight stay }\end{array}$} & 2 & 1.08 (0.81 to 1.45$)$ & 1.08 (0.81 to 1.44$)$ \\
\hline & 3 & 1.05 (0.82 to 1.34$)$ & 1.05 (0.82 to 1.33$)$ \\
\hline & 4 & 1.13 (0.81 to 1.59$)$ & 1.12 (0.80 to 1.56$)$ \\
\hline \multirow{4}{*}{$\begin{array}{l}\text { Likelihood of } \\
\text { an emergency } \\
\text { admission } \\
\text { resulting in an } \\
\text { overnight stay }\end{array}$} & 2 & 0.95 (0.67 to 1.34 ) & 0.97 (0.69. 1.35) \\
\hline & 3 & 1.20 (0.89 to 1.61$)$ & 1.23 (0.92 to 1.64$)$ \\
\hline & 4 & 1.28 (0.82 to 2.01$)$ & $1.18(0.77$ to 1.83$)$ \\
\hline & & Rate ratio $(\mathrm{Cl})$ & Rate ratio $(\mathrm{Cl})$ \\
\hline \multirow{3}{*}{$\begin{array}{l}\text { Average } \\
\text { length of stay } \\
\text { of overnight } \\
\text { emergency } \\
\text { admissions }\end{array}$} & 2 & 1.00 (0.78 to 1.27$)$ & 0.96 (0.75 to 1.22$)$ \\
\hline & 3 & 1.05 (0.86 to 1.28$)$ & 0.99 (0.81 to 1.21$)$ \\
\hline & 4 & 1.01 (0.75 to 1.35$)$ & 0.91 (0.68 to 1.23 ) \\
\hline \multirow{3}{*}{$\begin{array}{l}\text { Average } \\
\text { length of stay } \\
\text { of overnight } \\
\text { elective } \\
\text { admissions }\end{array}$} & 2 & 0.67 (0.45 to 1.01$)$ & 0.67 (0.45 to 1.00$)$ \\
\hline & 3 & 0.67 (0.48 to 0.94$)$ & 0.68 (0.49 to 0.96$)$ \\
\hline & 4 & 0.59 (0.37 to 0.94$)$ & 0.62 (0.40 to 0.99 ) \\
\hline
\end{tabular}

GP, general practitioner; PAM, Patient Activation Measure.

level and utilisation was statistically significant for both patients in the most socioeconomic deprived fifth of areas (53\% of the analysis cohort) and in other areas.
For patients living in the most socioeconomic deprived areas, the difference in healthcare utilisation between the high and lowest level of activation was greater, compared with those living in any other area (table 4).

\section{Sensitivity analysis}

When restricting the observation periods in our analysis to utilisation in the 6 months following receipt of the PAM questionnaire, while the power of the sample was reduced, we found that the pattern of associations between PAM level and main outcome measures was unchanged (online supplementary appendix 6). We did not run the analysis for readmission, and the length of stay for elective and emergency admissions, due to low sample size.

\section{DISCUSSION}

The rising demand for healthcare services, a large proportion of which is due to the growing population of people with long-term conditions, has led to a need to manage the increasing pressure placed on primary and secondary care. In this paper, we found that more activated patients used healthcare services less often, even after controlling for predictors of utilisation, such as diagnosed physical and mental health longterm conditions, gender, age and socioeconomic deprivation. Our findings suggest that supporting patients with long-term conditions to manage their own care is not only a key part of high-quality care, ${ }^{2}$ but could be associated with lower healthcare utilisation. This is particularly important at a time when health services are under strain.

There are several reasons why more activated patients might use less healthcare. They may be better engaged in the ongoing management of their conditions; consequently, their need for healthcare to manage deterioration in their condition is reduced compared with less active patients. Such patients may also be better equipped to coordinate their care, leading to fewer missed general practice and outpatient appointments. Another possibility is that there is some residual confounding in the data, with less activated patients having a higher burden of disease and therefore requiring more healthcare. Although we adjusted for factors observed within the routine data (such as individual diagnoses), we could not adjust for clinical severity. The possibility of residual confounding is an important one and would be properly addressed through an intervention study. This would fully address causality and could capitalise on the strength of the observed association, and the large effect size between self-management capability and healthcare utilisation we observe. In the adjusted analysis, being in PAM level 4 (compared with level 1) was associated with $18 \%$ fewer contacts with a general practitioner, $32 \%$ fewer attendances at an emergency department, 38\% fewer emergency admissions, and 20\% and 19\% fewer 
Table 3 Sensitivity analysis of the repeated measures mixed models: clinical subgroups

\begin{tabular}{|c|c|c|c|c|c|}
\hline & & $\begin{array}{l}\text { No mental health } \\
\text { long-term conditions }\end{array}$ & $\begin{array}{l}\text { Mental health long- } \\
\text { term condition }\end{array}$ & $\begin{array}{l}\text { 2+ Long-term } \\
\text { conditions }\end{array}$ & $\begin{array}{l}\text { 3+ Long-term } \\
\text { conditions }\end{array}$ \\
\hline Outcome & PAM level (vs 1) & Rate ratio $(\mathrm{Cl})$ & Rate ratio $(\mathrm{Cl})$ & Rate ratio $(\mathrm{Cl})$ & Rate ratio $(\mathrm{Cl})$ \\
\hline \multirow{3}{*}{$\begin{array}{l}\text { Contact with a general } \\
\text { practitioner }\end{array}$} & 2 & 0.93 (0.89 to 0.98$)$ & $0.88(0.83$ to 0.94$)$ & $0.93(0.89$ to 0.97$)$ & $0.94(0.89$ to 1.00$)$ \\
\hline & 3 & $0.87(0.84$ to 0.91$)$ & $0.87(0.82$ to 0.92$)$ & $0.88(0.85$ to 0.92$)$ & $0.89(0.85$ to 0.94$)$ \\
\hline & 4 & 0.84 (0.79 to 0.89$)$ & $0.79(0.72$ to 0.86$)$ & 0.81 (0.77 to 0.86$)$ & $0.86(0.80$ to 0.93$)$ \\
\hline \multirow{3}{*}{$\begin{array}{l}\text { Emergency department } \\
\text { attendance }\end{array}$} & 2 & 0.76 (0.67 to 0.87$)$ & 0.77 (0.65 to 0.92$)$ & 0.83 (0.73 to 0.93$)$ & $0.84(0.72$ to 0.98$)$ \\
\hline & 3 & 0.74 (0.66 to 0.83$)$ & 0.71 (0.61 to 0.82$)$ & $0.77(0.69$ to 0.85$)$ & $0.77(0.67$ to 0.88$)$ \\
\hline & 4 & $0.71(0.61$ to 0.82$)$ & $0.65(0.52$ to 0.81$)$ & $0.68(0.59$ to 0.80$)$ & $0.68(0.56$ to 0.84$)$ \\
\hline \multirow[t]{3}{*}{ Elective admission } & 2 & $0.85(0.72$ to 1.00$)$ & 0.83 (0.65 to 1.06$)$ & 0.88 (0.75 to 1.03$)$ & $0.82(0.66$ to 1.01$)$ \\
\hline & 3 & 0.79 (0.69 to 0.92$)$ & $0.74(0.60$ to 0.90$)$ & $0.83(0.72$ to 0.95$)$ & $0.90(0.75$ to 1.07$)$ \\
\hline & 4 & 0.85 (0.70 to 1.03$)$ & 0.68 (0.49 to 0.93$)$ & 0.82 (0.68 to 1.01$)$ & $0.82(0.63$ to 1.07$)$ \\
\hline \multirow[t]{3}{*}{ Emergency admission } & 2 & $0.76(0.62$ to 0.92$)$ & 0.65 (0.49 to 0.85$)$ & 0.69 (0.58 to 0.83$)$ & $0.65(0.52$ to 0.81$)$ \\
\hline & 3 & 0.69 (0.58 to 0.81$)$ & 0.62 (0.50 to 0.77$)$ & $0.69(0.59$ to 0.80$)$ & $0.71(0.59$ to 0.85$)$ \\
\hline & 4 & 0.68 (0.54 to 0.86$)$ & $0.51(0.36$ to 0.73$)$ & $0.62(0.50$ to 0.77$)$ & 0.55 (0.41 to 0.73$)$ \\
\hline \multirow{3}{*}{$\begin{array}{l}\text { Attended outpatient } \\
\text { appointment }\end{array}$} & 2 & 0.90 (0.82 to 0.99$)$ & 0.88 (0.77 to 1.01$)$ & 0.91 (0.83 to 0.99) & $0.92(0.82$ to 1.03$)$ \\
\hline & 3 & $0.86(0.79$ to 0.94$)$ & 0.91 (0.81 to 1.02$)$ & $0.88(0.82$ to 0.95$)$ & 0.91 (0.82 to 1.01$)$ \\
\hline & 4 & $0.82(0.74$ to 0.91$)$ & 0.75 (0.63 to 0.89$)$ & $0.80(0.72$ to 0.90$)$ & $0.87(0.75$ to 1.01$)$ \\
\hline \multirow{3}{*}{$\begin{array}{l}\text { 'Did not attend' a } \\
\text { GP contact }\end{array}$} & 2 & $0.93(0.82$ to 1.06$)$ & $0.87(0.74$ to 1.01$)$ & $0.90(0.80$ to 1.01$)$ & 0.89 (0.76 to 1.03$)$ \\
\hline & 3 & 0.85 (0.76 to 0.95$)$ & $0.84(0.74$ to 0.96$)$ & $0.87(0.79$ to 0.96$)$ & $0.87(0.77$ to 0.99$)$ \\
\hline & 4 & 0.78 (0.67 to 0.91$)$ & 0.74 (0.60 to 0.92$)$ & 0.74 (0.64 to 0.85$)$ & $0.74(0.61$ to 0.91$)$ \\
\hline \multirow{3}{*}{$\begin{array}{l}\text { 'Did not attend' an } \\
\text { outpatient appointment }\end{array}$} & 2 & $0.89(0.74$ to 1.06$)$ & $0.63(0.49$ to 0.80$)$ & 0.78 (0.67 to 0.92$)$ & 0.65 (0.53 to 0.8$)$ \\
\hline & 3 & 0.72 (0.62 to 0.84$)$ & $0.64(0.52$ to 0.78$)$ & 0.70 (0.61 to 0.81$)$ & 0.65 (0.55 to 0.78$)$ \\
\hline & 4 & 0.78 (0.63 to 0.96$)$ & $0.66(0.48$ to 0.90$)$ & 0.72 (0.59 to 0.89$)$ & $0.57(0.43$ to 0.76$)$ \\
\hline \multirow{3}{*}{$\begin{array}{l}\text { Minor self-referral to an } \\
\text { emergency department }\end{array}$} & 2 & 0.86 (0.70 to 1.05$)$ & 1.03 (0.79 to 1.34$)$ & 1.04 (0.86 to 1.25$)$ & 1.13 (0.88 to 1.44$)$ \\
\hline & 3 & 0.77 (0.65 to 0.92) & $0.77(0.62$ to 0.96$)$ & $0.80(0.68$ to 0.94$)$ & $0.82(0.66$ to 1.01$)$ \\
\hline & 4 & 0.69 (0.54 to 0.87$)$ & $0.64(0.44$ to 0.91$)$ & $0.67(0.52$ to 0.85$)$ & $0.62(0.43$ to 0.87$)$ \\
\hline
\end{tabular}

$\mathrm{GP}$, general practitioner; PAM, Patient Activation Measure.

elective admissions and outpatient appointments, respectively. Importantly, patients in PAM level 4 had an average length of stay for overnight elective inpatient admissions of $41 \%$ shorter than those in PAM level 1 . When looking at markers of wasteful utilisation, patients in PAM level 4 had 33\% fewer self-referrals to an emergency department that are of 'minor severity', and 23\% and 28\% fewer 'did not attends' at appointments with general practitioners and in outpatient settings, respectively. Patterns observed in the subgroup analysis demonstrated that the link between self-management capability and healthcare utilisation may be more pronounced in certain groups. For patients with a mental health condition or from socioeconomically deprived areas, there was a larger difference in utilisation between the highest and lowest activated patients. We did not find that the association changed in patients with three or more, or two or more conditions. In older patients (over 75), while the trends observed were often consistent with other patient groups, the association between activation level and utilisation did not reach significance in most outcomes.

There has been no research on the association between patient activation and healthcare utilisation across primary and secondary care in a healthcare system that is comparable in structure, access and funding to the English NHS. However, previous studies in the USA have found a similar association between increased activation and lower emergency department attendances and inpatient admissions for patients with heart failure, ${ }^{19}$ patients with diabetes ${ }^{20} 21$ and a general patient cohort in one provider system. ${ }^{15}$ There is no comparable research with ours that examines the association between patient self-management and inefficient usage of general practice, outpatient department or emergency departments. However, previous research has indicated an association between younger age, underlying psychological problems and socioeconomic deprivation and 'did not attends' at healthcare contacts, which is consistent with our findings. $^{33} 34$

\section{Strengths and limitations}

The analysis in this study used detailed individual-level linked primary and secondary care records for a large cohort of patients, with a long period of registration with a GP. The setting was a health economy with a single payer commissioning care for the whole population, which is free at the point of use. This data set allowed us to estimate the association between a patient's activation and their 
Table 4 Sensitivity analysis of the repeated measures mixed models: demographic subgroups

\begin{tabular}{|c|c|c|c|c|c|}
\hline & & Aged below 75 & Aged 75 and over & $\begin{array}{l}\text { Most deprived IMD } \\
\text { quintile }\end{array}$ & $\begin{array}{l}\text { Any other IMD } \\
\text { quintile }\end{array}$ \\
\hline Outcome & PAM level (vs 1) & Rate ratio $(\mathrm{Cl})$ & Rate ratio $(\mathrm{Cl})$ & Rate ratio $(\mathrm{Cl})$ & Rate ratio $(\mathrm{Cl})$ \\
\hline \multirow{3}{*}{$\begin{array}{l}\text { Contact with a general } \\
\text { practitioner }\end{array}$} & 2 & $0.86(0.82$ to 0.90$)$ & 1.03 (0.97 to 1.10$)$ & 0.90 (0.86 to 0.95$)$ & $0.93(0.88$ to 0.99$)$ \\
\hline & 3 & $0.83(0.80$ to 0.87$)$ & $0.96(0.91$ to 1.01$)$ & $0.87(0.83$ to 0.91$)$ & $0.87(0.83$ to 0.91$)$ \\
\hline & 4 & $0.77(0.73$ to 0.81$)$ & 0.96 (0.88 to 1.04$)$ & 0.84 (0.79 to 0.89$)$ & 0.81 (0.76 to 0.86$)$ \\
\hline \multirow{3}{*}{$\begin{array}{l}\text { Emergency department } \\
\text { attendance }\end{array}$} & 2 & 0.72 (0.63 to 0.82 ) & 0.85 (0.71 to 1.02$)$ & 0.73 (0.64 to 0.84$)$ & $0.82(0.70$ to 0.96$)$ \\
\hline & 3 & $0.71(0.64$ to 0.80$)$ & 0.77 (0.67 to 0.89$)$ & 0.75 (0.66 to 0.84$)$ & $0.72(0.63$ to 0.82$)$ \\
\hline & 4 & $0.65(0.56$ to 0.76$)$ & $0.81(0.65$ to 1.01$)$ & 0.65 (0.54 to 0.77$)$ & $0.74(0.62$ to 0.89$)$ \\
\hline \multirow{3}{*}{ Elective admission } & 2 & 0.77 (0.65 to 0.91$)$ & 0.99 (0.78 to 1.25$)$ & 0.82 (0.68 to 0.98$)$ & $0.87(0.71$ to 1.07$)$ \\
\hline & 3 & $0.69(0.60$ to 0.79$)$ & 0.97 (0.79 to 1.18$)$ & 0.79 (0.68 to 0.93$)$ & $0.75(0.63$ to 0.90$)$ \\
\hline & 4 & $0.69(0.57$ to 0.83$)$ & 1.13 (0.83 to 1.54$)$ & $0.77(0.62$ to 0.96$)$ & $0.83(0.65$ to 1.05$)$ \\
\hline \multirow[t]{3}{*}{ Emergency admission } & 2 & $0.70(0.56$ to 0.87$)$ & 0.75 (0.60 to 0.94$)$ & $0.66(0.53$ to 0.81$)$ & $0.79(0.62$ to 1.00$)$ \\
\hline & 3 & 0.70 (0.59 to 0.84$)$ & 0.64 (0.53 to 0.77$)$ & $0.67(0.56$ to 0.80$)$ & $0.64(0.52$ to 0.78$)$ \\
\hline & 4 & 0.60 (0.47 to 0.77$)$ & 0.73 (0.54 to 0.98$)$ & 0.55 (0.42 to 0.73$)$ & 0.70 (0.53 to 0.92$)$ \\
\hline \multirow{3}{*}{$\begin{array}{l}\text { Attended outpatient } \\
\text { appointment }\end{array}$} & 2 & 0.85 (0.78 to 0.94$)$ & 0.97 (0.86 to 1.10$)$ & 0.89 (0.8 to 0.98$)$ & $0.91(0.81$ to 1.01$)$ \\
\hline & 3 & 0.85 (0.78 to 0.93$)$ & 0.92 (0.83 to 1.03 ) & $0.92(0.84$ to 1.00$)$ & $0.83(0.75$ to 0.91$)$ \\
\hline & 4 & 0.76 (0.68 to 0.85$)$ & 0.91 (0.77 to 1.08$)$ & $0.83(0.73$ to 0.94$)$ & $0.78(0.68$ to 0.89$)$ \\
\hline \multirow{3}{*}{$\begin{array}{l}\text { 'Did not attend' a GP } \\
\text { contact }\end{array}$} & 2 & $0.96(0.85$ to 1.08$)$ & 0.82 (0.69 to 0.97$)$ & $0.92(0.81$ to 1.05$)$ & $0.88(0.76$ to 1.03$)$ \\
\hline & 3 & $0.87(0.78$ to 0.96$)$ & 0.82 (0.71 to 0.95$)$ & $0.82(0.73$ to 0.91$)$ & $0.89(0.79$ to 1.01$)$ \\
\hline & 4 & $0.78(0.68$ to 0.90$)$ & 0.75 (0.59 to 0.95$)$ & 0.81 (0.69 to 0.95$)$ & $0.72(0.60$ to 0.87$)$ \\
\hline \multirow{3}{*}{$\begin{array}{l}\text { 'Did not attend' an } \\
\text { outpatient appointment }\end{array}$} & 2 & 0.70 (0.59 to 0.84$)$ & $0.90(0.72$ to 1.14$)$ & $0.77(0.65$ to 0.93$)$ & 0.83 (0.67 to 1.04$)$ \\
\hline & 3 & 0.70 (0.61 to 0.82$)$ & $0.63(0.51$ to 0.78$)$ & 0.71 (0.6 to 0.83$)$ & $0.68(0.56$ to 0.82$)$ \\
\hline & 4 & 0.77 (0.63 to 0.93) & $0.62(0.44$ to 0.87$)$ & $0.68(0.54$ to 0.85$)$ & $0.82(0.63$ to 1.06$)$ \\
\hline \multirow{3}{*}{$\begin{array}{l}\text { Minor self-referral to an } \\
\text { emergency department }\end{array}$} & 2 & 0.82 (0.67 to 0.99$)$ & 1.14 (0.85 to 1.51$)$ & $0.80(0.65$ to 1.00$)$ & $1.07(0.84$ to 1.36$)$ \\
\hline & 3 & 0.71 (0.60 to 0.83$)$ & $0.94(0.74$ to 1.21$)$ & 0.77 (0.65 to 0.93$)$ & 0.79 (0.64 to 0.98$)$ \\
\hline & 4 & 0.61 (0.49 to 0.77$)$ & $0.88(0.60$ to 1.31$)$ & $0.64(0.49$ to 0.84$)$ & $0.74(0.56$ to 0.98$)$ \\
\hline
\end{tabular}

GP, general practitioner; IMD, Index of Multiple Deprivation; PAM, Patient Activation Measure.

utilisation over a wide range of outcomes (including wasteful usage) and to examine whether patterns of underutilisation or overutilisation in one sector (eg, primary care) were mirrored (or compensated for) in emergency and secondary care, while appropriately controlling for a range of likely confounders.

This was a population-wide study which achieved a response rate of $17.2 \%$ and $15.4 \%$ in the 2 years the PAM questionnaire was sent to all patients with 1 of 14 long-term conditions, in Islington, London. In previous large studies in the USA, the proportion of the patient population who completed a questionnaire each year ranged from $18 \%$ to $54 \%,{ }^{1421}{ }^{35-40}$ which is higher than our response rates. A potential explanation lies in the tendency, observed in those previous studies, of response rates to be higher when PAM data are mandated as part of service enrolment. ${ }^{35}$ In our study, patients were not required to respond to the questionnaires to access NHS healthcare. Nevertheless, the low response rate limits the generalisability of our findings. We can only analyse patients who returned a PAM questionnaire; in our analysis we found that older age, and higher GP, inpatient and outpatient utilisation were predictive of response rates. Therefore, our findings may not generalise to all those living with long-term conditions. Furthermore, compared with the English average, Islington is relatively urban, deprived, ethnically diverse and has a young population with a high burden of chronic disease, ${ }^{41}$ and so further studies are required in other populations to further aid the design of interventions. Nevertheless, Islington CCG is the only setting, outside the USA, where the PAM has been collected to date from a whole population of patients, allowing a study such as the current one.

The PAM, which we use to measure patients' ability to manage their own care, has strengths; it is psychometrically validated, ${ }^{37}$ translated into a wide range of languages (and dialects), ${ }^{31}$ with language tailored to the local health system, and measures a spectrum of skills, knowledge and confidence in patients. ${ }^{42}$ However, patient activation is a self-assessment of a patient's ability to manage their own care, rather than the direct measurement of self-management behaviour, although this will be true of any self-assessed measure.

As mentioned above, while we adjusted for a wide range of demographic, socioeconomic and clinical confounders that were recorded on patients' electronic health records, it is possible that there is residual confounding in the data, or that unobserved characteristics, such as education and social support, are associated with both low activation and high utilisation. We also cannot determine the direction of 
the association fully, although our sensitivity analysis where we restricted the utilisation that we examined to the 6 months following the PAM collection partly addresses this. These factors merit further research. Finally, our analysis cannot determine whether increasing a patient's self-management capability is possible, or will be associated with a subsequent decrease in health service usage.

\section{Implications and conclusions}

Our findings suggest that patients' ability to manage their own health and healthcare is inversely related to primary and secondary care utilisation and inefficient utilisation. This underlines the importance of promoting self-management capability, especially when services have rising demand for care and constrained resources. Broadly, there are two main strategies that clinicians and commissioners could take in response to our findings for managing patients with long-term conditions: either intervening to improve the self-management capability of their patients, or adapting the approach they take to delivering a patient's care to the level of ability of the patient.

In the case of the first strategy, although limited, some studies have shown improvements in patient activation in response to interventions, such as an online diabetes self-management programme. ${ }^{43}$ A qualitative study of physician strategies identified goal setting, care planning and elements of health coaching and education as encouraging improvements in activation. ${ }^{44}$ The associations we observed in our study are not causative, and indeed the direction of the relationship cannot be confirmed with the data set and methods available. However, it demonstrates the potential of such methods to reduce inefficient utilisation across the health system. Certain cohorts of patients, where the most benefit could be realised, could be targeted for intervention, for example patients with long-term conditions (such as those living in areas of high socioeconomic deprivation or those with mental health conditions). Our findings should motivate and inform the design of interventions to improve activation.

In the case of the second strategy, currently, at national and regional levels, policies and initiatives have attempted to address the health needs of high utilisation patients through coordinated and integrated care, ${ }^{78}$ with the aim of reducing the demand for acute and emergency care. Such approaches for younger patients, particularly those with comorbid mental health conditions or from areas of socioeconomic deprivation, ${ }^{45}$ could potentially be improved through using the PAM to target and tailor approaches to a patient's level of activation. Programmes of care that require high levels of engagement and self-management from patients, for example remote self-monitoring, ${ }^{46}$ could be aimed at those with developed self-management capability, while patients with less developed self-management capacity are prioritised for extra support such as health coaches. ${ }^{47}$ Clinicians and commissioners could then more appropriately address the non-clinical needs of patients and reduce inappropriate use of the healthcare system, and improvements in patient outcomes.

One aim of health systems is to enable patients to manage their own care more in order to improve outcomes, to reduce demand on the service and to reduce inefficient usage. However, little has been known about the potential reductions in demand for the range of services in a local health economy, if the system was able to enable patients to better manage their own care. Therefore it has been difficult for policymakers to prioritise this aim over others. We show that patients who feel they are more able to manage their conditions use less healthcare across a healthcare system, as well as have less wasteful utilisation. Therefore, our results suggest that a further focus from policymakers and clinicians in understanding the self-management capability of patients, and the design of interventions which support this, could be beneficial for the health system as a whole.

Acknowledgements We thank Phil Wrigley and Katie Coleman from Islington Clinical Commissioning Group for their support and direction. Also, thanks to Laurence and Ryan at North East London Commissioning Support Unit and the Data Management Team at The Health Foundation for their work in identifying and preparing the data extract, and managing information governance and data sharing processes. Additionally, thanks to Natalie Armstrong and Sarah Chew at the University of Leicester and all in the NHS England PAM learning set for their insightful discussion throughout the project.

Contributors AS and SRD conceived the study. IB, AS and SRD designed the statistical analysis plan. SRD, IB and RW carried out the analysis. IB, SRD and AS drafted and finalised the paper.

Funding All authors had financial support from The Health Foundation for the submitted work.

Competing interests None declared.

Patient consent Not required.

Provenance and peer review Not commissioned; externally peer reviewed.

Data sharing statement PAM questionnaires were collected as part of routine care and uploaded to the electronic health record. As we used routinely collected and pseudonymised data for our analysis, with a data sharing agreement approved by the Islington CCG data holders, no further ethics approval was required. However, due to the data sharing agreement, data cannot be made publicly available with this study.

Open access This is an open access article distributed in accordance with the Creative Commons Attribution Non Commercial (CC BY-NC 4.0) license, which permits others to distribute, remix, adapt, build upon this work noncommercially, and license their derivative works on different terms, provided the original work is properly cited and the use is non-commercial. See: http://creativecommons.org/licenses/ by-nc/4.0/

(C) Article author(s) (or their employer(s) unless otherwise stated in the text of the article) 2018. All rights reserved. No commercial use is permitted unless otherwise expressly granted. 


\section{REFERENCES}

1 Department of Health. Improving the health and well-being of people with long term conditions. London: Department of Health, 2010.

2 Coleman K, Austin BT, Brach C, et al. Evidence on the Chronic Care Model in the new millennium. Health Aff 2009;28:75-85.

3 NHS England. Five year forward view. London: NHS England, 2014.

4 Fraze T, Lewis VA, Rodriguez HP, et al. Housing, Transportation, And Food: How ACOs Seek To Improve Population Health By Addressing Nonmedical Needs Of Patients. Health Aff 2016;35:2109-15.

5 Sinaiko AD, Landrum MB, Meyers DJ, et al. Synthesis Of Research On Patient-Centered Medical Homes Brings Systematic Differences Into Relief. Health Aff 2017;36:500-8.

6 Leppin AL, Gionfriddo MR, Kessler M, et al. Preventing 30-day hospital readmissions: a systematic review and meta-analysis of randomized trials. JAMA Intern Med 2014;174:1095-107.

7 Roland M, Lewis R, Steventon A, et al. Case management for at-risk elderly patients in the English integrated care pilots: observational study of staff and patient experience and secondary care utilisation. Int J Integr Care 2012;12:e130.

8 Nelson L, Buntin M, Baumgardner J, et al. Working Paper Series Congressional Budget Office Lessons from Medicare's Demonstration Projects on Disease Management and Care Coordination Lessons from Medicare's Demonstration Projects on Disease Management and Care Coordination. 2012.

9 Stokes J, Panagioti M, Alam R, et al. Effectiveness of Case Management for 'At Risk' Patients in Primary Care: A Systematic Review and Meta-Analysis. PLoS One 2015;10:e0132340.

10 Abrams MKA, Doty MMD, Ryan JR, et al. How High-Need Patients Experience Health Care in the United States: Findings from the 2016 Commonwealth Fund Survey of High-Need Patients. 2016.

11 PACIC Survey. Improving Chronic Illness Care. http://www. improvingchroniccare.org/index.php?p $=$ PACIC_survey\&s $=36$ (accessed 6 Mar 2018).

12 Mishali M, Omer H, Heymann AD. The importance of measuring self-efficacy in patients with diabetes. Fam Pract 2011;28:82-7.

13 NHS England. PAM learning set. https://www.england.nhs. uk/ourwork/patient-participation/self-care/patient-activation/ pamlearning/.

14 Greene J, Hibbard JH. Why does patient activation matter? An examination of the relationships between patient activation and health-related outcomes. J Gen Intern Med 2012;27:520-6.

15 Hibbard JH, Greene J, Overton V. Patients With Lower Activation Associated With Higher Costs; Delivery Systems Should Know Their Patients' 'Scores'. Health Aff 2013;32:216-22.

16 Greene J, Hibbard JH, Sacks R, et al. When patient activation levels change, health outcomes and costs change, too. Health Aff 2015;34:431-7.

17 Hibbard JH, Mahoney ER, Stock R, et al. Do increases in patient activation result in improved self-management behaviors? Health Serv Res 2007;42:1443-63.

18 Hibbard J, Helen G. Supporting people to manage their health: an introduction to patient activation. London: King's Fund, 2014.
19 Shively MJ, Gardetto NJ, Kodiath MF, et al. Effect of patient activation on self-management in patients with heart failure. $J$ Cardiovasc Nurs 2013;28:20-34.

20 Remmers C, Hibbard J, Mosen DM, et al. Is Patient Activation Associated With Future Health Outcomes and Healthcare Utilization Among Patients With Diabetes? J Ambul Care Manage 2009;32:320-7.

21 Begum N, Donald M, Ozolins IZ, et al. Hospital admissions, emergency department utilisation and patient activation for self-management among people with diabetes. Diabetes Res Clin Pract 2011;93:260-7.

22 Department for Communities and Local Government. English indices of deprivation 2010. 2011 https://www.gov.uk/ government/statistics/english-indices-of-deprivation-2010.

23 Young HN, Larson TL, Cox ED, et al. The active patient role and asthma outcomes in an underserved rural community. $J$ Rural Health 2014;30:121-7.

24 Office of National Statistics. Population estimates. http:// www.ons.gov.uk/ons/taxonomy/index.html?nscl=Population + Estimates.

25 NHS Employers. 2014/15 General Medical Services (Gms) Contract Quality and Outcomes Framework (Qof). 2014 http://www.nhsemployers.org/ /media/Employers/Documents/ Primary care contracts/QOF/2014-15/2014-15-GeneralMedical-Services-contract-Quality-and-Outcomes-FrameworkGuidannce-for-GMS-contract-2014-15.pdf.

26 NHS England. Emergency readmissions within 30 days of discharge from hospital - Datasets - NHS England Data Catalogue. 2014. https://data.england.nhs.uk/dataset/ccgois-32-emergency-readmissions-within-30-days-of-discharge-fromhospital (accessed 17 Jul 2017).

27 Whittaker W, Anselmi L, Kristensen SR, et al. Associations between extending access to primary care and emergency department visits: a difference-in-differences analysis. PLoS Med 2016;13:e1002113.

28 Billings J, Georghiou T, Blunt I, et al. Choosing a model to predict hospital admission: an observational study of new variants of predictive models for case finding. BMJ Open 2013;3:e003352.

29 Lewis G, Curry N, Bardsley M. Choosing a predictive risk model : a guide for commissioners in England. London: Nuffield Trust, 2011.

30 Akaike H. A new look at the statistical model identification. IEEE Trans Automat Contr 1974;19:716-23.

31 Armstrong N, Tarrant C, Martin G, et al. Independent evaluation of the feasibility of using the Patient Activation Measure in the NHS In England: Summary Interim Report. 2016 https:/www.england.nhs.uk/wp-content/uploads/2016/ 04/pa-interim-report-summary.pdf.

32 England N. SUS PbR Reference Manual Implementation of National Tariff / Payment by Results (PbR) policy in the Secondary Uses Service. London: NHS Digital, 2016.

33 George A, Rubin G. Non-attendance in general practice: a systematic review and its implications for access to primary health care. Fam Pract 2003;20:178-84.

34 Neal RD, Hussain-Gambles M, Allgar VL, et al. Reasons for and consequences of missed appointments in general practice in the UK: questionnaire survey and prospective review of medical records. BMC Fam Pract 2005;6:47.

35 Hibbard JH, Greene J, Overton V. Patients with lower activation associated with higher costs; delivery systems should know their patients' 'scores'. Health Aff 2013;32:216-22. 
36 Rask KJ, Ziemer DC, Kohler SA, et al. Patient activation is associated with healthy behaviors and ease in managing diabetes in an indigent population. Diabetes Educ 2009;35:622-30.

37 Skolasky RL, Green AF, Scharfstein D, et al. Psychometric properties of the patient activation measure among multimorbid older adults. Health Serv Res 2011;46:457-78.

38 Mitchell SE, Gardiner PM, Sadikova E, et al. Patient activation and 30-day post-discharge hospital utilization. J Gen Intern Med 2014;29:349-55.

39 Remmers C, Hibbard J, Mosen DM, et al. Is patient activation associated with future health outcomes and healthcare utilization among patients with diabetes? J Ambul Care Manage 2009;32:320-7.

40 Mosen DM, Schmittdiel J, Hibbard J, et al. Is patient activation associated with outcomes of care for adults with chronic conditions? J Ambul Care Manage 2007;30:21-9.

41 Islington Clinical Commissioning Group. The Islington Population. 2009 http://www.islingtonccg.nhs.uk/jsna/ Introduction-and-The-Islington-Population-JSNA-200910.pdf (accessed 17 Jul 2017).

42 Hibbard JH, Stockard J, Mahoney ER, et al. Development of the Patient Activation Measure (PAM): conceptualizing and measuring activation in patients and consumers. Health Serv Res 2004;39:1005-26.

43 Lorig K, Ritter PL, Laurent DD, et al. Online diabetes selfmanagement program. Diabetes Care 2010;33:1275-81.

44 Greene J, Hibbard JH, Alvarez C, et al. Supporting patient behavior change: approaches used by primary care clinicians whose patients have an increase in activation levels. Ann Fam Med 2016;14:148-54.

45 Mercer SW, Fitzpatrick B, Guthrie B, et al. The CARE Plus study - a whole-system intervention to improve quality of life of primary care patients with multimorbidity in areas of high socioeconomic deprivation: exploratory cluster randomised controlled trial and cost-utility analysis. BMC Med 2016;14:88.

46 Panagioti M, Richardson G, Small N, et al. Self-management support interventions to reduce health care utilisation without compromising outcomes: a systematic review and metaanalysis. BMC Health Serv Res 2014;14:356.

47 Jonk Y, Lawson K, O'Connor H, et al. How effective is health coaching in reducing health services expenditures? Med Care 2015;53:133-40. 